\title{
COMUNICAÇÃO
}

\section{OCORRÊNCIA DE BIOMPHALARIA STRAMINEA (PULMONATA: PLANORBIDAE) NA ESTACÃO DE AQÜICULTURA DO IBAMA EM UBERLÂNDIA, MG}

\author{
Elisângela de Paula Silveira, Oswaldo Marçal Junior \\ e Maria Inês Machado
}

\begin{abstract}
Este trabalho avalia a ocorrência de moluscos planorbídeos na estação de psicultura do IBAMA em Uberlândia, Minas Gerais. Constatou-se a presença de Biomphalaria straminea em 39,5\% dos tanques de criação. Nenhum dos caramujos estava infectado por Schistosoma mansoni, mas investigações complementares devem ser realizadas na área.
\end{abstract}

Palavras-chaves: Biomphalaria straminea. Moluscos planorbídeos. Criação de peixes.

A distribuição geográfica de algumas das principais doenças infecciosas humanas é condicionada pela disponibilidade de vetores 3 e esta relação pode ser exemplificada pela ocorrência da esquistossomose mansônica no Brasil. A endemia foi introduzida no país com o tráfico de escravos africanos e, certamente, outras espécies de Schistosoma aqui teriam sido instaladas se existissem hospedeiros intermediánios adequados; além disso, as áreas de transmissão da parasitose mostram uma íntima associação com a distribuição espacial de Biomphalaria glabrata (Say, 1818), B. tenagophila (Orbigny, 1835) e B. straminea (Dunker, 1848), as três únicas espécies de moluscos planorbídeos que, em condições naturais, transmitem o S. mansoni em nosso meio 567 .

É evidente que a ampliação das áreas de vida de qualquer uma dessas espécies de Biomphalaria implica em um aumento do potencial endêmico da esquistossomose, exigindo um acompanhamento constante. No presente trabalho, apresentamos os resultados de levantamento da fauna planorbídica realizado na Estação de Aqüicultura de Uberlândia, do Instituto Brasileiro do Meio Ambiente e dos Recursos Naturais Renováveis (IBAMA) e avaliamos a importância epidemiológica dos achados.

Endereço para correspondência: Prof. Oswaldo Marçal Junior, Depto. de Biociências, Centro de Ciências Biomédicas, Universidade Federal de Uberlândia, Rua Ceará s/no, Campus Umuarama, C.P. 593, 38400-902 Uberlândia, MG, Brasil.TeleFax: (034) 218-2243.

Recebido para publicação em 18/11/96.
A primeira Estação de Psicultura de Uberândia, município localizado na região do Triângulo, Estado de Minas Gerais, foi criada em 1957 e situava-se na fazenda Semente. Em 1970, esta estação foi transferida para a zona urbana de Uberlândia, passando a ser administrada pela Superintendência de Desenvolvimento de Pesca (SUDEPE). Localizada na rua Sudepe, bairro Tubalina - Setor de Chácaras, tem como principal objetivo a criação de espécies de peixes nativas e procedentes de outros Estados para adpatação e introdução nos rios da região. Com uma área de 4,8 hectares, a estação possui um total de 38 tanques de criação, construídos de cimento com fundo forrado de areia ou totalmente de terra, com profundidade média de 2 metros. Todos os tanques são interligados por uma rede de ductos e canais, de forma que o tanque $\mathrm{n}-1$ se liga ao $\mathrm{n}-2$ e assim sucessivamente. $\mathrm{O}$ córrego do Óleo é utilizado tanto para o abastecimento quanto para a drenagem do sistema.

No período de outubro de 1995 a março de 1996, foram realizadas três pesquisas bimestrais para investigar a presença de moluscos planorbídeos na estação de psicultura. Foi empregado o método de conchadas 8 , sendo dadas duas conchadas por metro de perímetro em cada um dos tanques. Tanto as margens como o fundo dos tanques foram investigados. Os exemplares capturados foram acondicionados em frascos coletores, contendo água do próprio criadouro, e rotulados com código do tanque, número de caramujos, data, localização do criadouro e nome do coletor.

A identificação dos espécimes de planorbídeos foi realizada segundo características morfológicas 
Comunicação. Silveira EP, Marçal Jr O, Machado MI. Ocorrência de Biomphalaria straminea (Pulmonata: Planorbidae) na Estação de Aqüicultura do IBAMA em Uberlândia, MG. Revista da Sociedade Brasileira de Medicina Tropical 30:401-403, set-out, 1997.

das conchas e estruturas internas, de acordo com Paraense6, sendo a mesma confirmada pelo Depatamento de Parasitologia da Universidade Estadual de Campinas (UNICAMP). Todos os moluscos capturados foram expostos a luz artificial (lâmpada de $60 \mathrm{~W}$ ) durante 40 a 60 minutos para avaliação da infecção por Schistosoma mansoni.

Dos 38 tanques analisados, 15 (39,5\%) estavam colonizados por moluscos planorbídeos. Foram capturados 916 caramujos aderidos às paredes, à vegetação marginal $\mathrm{e} / \mathrm{ou}$ ao fundo dos tanques, a maioria dos quais ( 804 exemplares) na terceira e última pesquisa, realizada entre fevereiro e março de 1996 (Figura 1). Biomphalaria straminea foi a única espécie de planorbídeo encontrada e nenhum dos exemplares estava infectado por S. mansoni. Note-se que $40 \%$ dos moluscos apresentavamse infectados por Cercaria caratinguensis.
A ocomência de B. straminea na estação de psicultura do IBAMA em Uberlândia apresenta um grande interesse epidemiológico, já que nas últimas décadas diversos trabalhos têm demonstrado a importância de plantas aquáticas e peixes como veículos de dispersão de moluscos hospedeiros intermediários de S. mansoni1 24 . Devemos lembrar ainda que esta espécie é reconhecida por sua extraordinária capacidade de adaptação e pelo fato de representar o principal hospedeiro intermediário do S. mansoni nas áreas endêmicas do nordeste brasileiro6 7 . Assim, embora não exista qualquer evidência de transmissão da esquistossomose em Uberlândia, acreditamos que seja necessário intensificar as investigações malacológicas no município e região, como também redobrar a vigilância epidemiológica nesta área. Neste sentido, notificamos, por intermédio da reitoria da Universidade Federal de Uberlândia, as autoridades competentes



Figura 1 - Tanques positivos para presença de Biomphalaria straminea na Estacão de Aqüicultura do IBAMA, segundo pesquisas realizadas no período de outubro de 95 a março de 96 - Uberlândia, MG.

sobre os resultados obtidos na presente pesquisa, e passamos a investigar o córrego do Óleo em toda a sua extensão, com intuito de identificar outros criadouros de moluscos planorbídeos, estabelecer seu potencial endêmico e avaliar as possíveis fontes de colonização dos tanques de criação de peixes daquela estação.

\section{SUMMARY}

This work evaluates the occurrence of freshwater snails in the IBAMA's fish breeding station in Uberlandia, Minas Gerais State. We verified the presence of Biomphalaria straminea in $39.5 \%$ of all breeding tanks. None of the snails were infected by
Schistosoma mansoni, but futher investigation should be done in the area.

Key-words: Biomphalaria straminea. Freshwater snails. Fish breeding sites. 
Comunicação. Silveira EP, Marçal Jr O, Machado MI. Ocorrência de Biomphalaria straminea (Pulmonata: Planorbidae) na Estação de Aqüicultura do IBAMA em Uberlândia, MG. Revista da Sociedade Brasileira de Medicina Tropical 30:401-403, set-out, 1997.

\section{REFERÊNCIAS BIBLIOGRÁFICAS}

1. Corrêa LC, Corrêa MDA, Vaz JF, Silva MIPG, Silva RM, Yamanaka MT. Importância de plantas ornamentais dos aquários como veículos de propagação de vetores de Schistosoma mansoni. Revista do Instituto Adolfo Lutz 40:89-96, 1980.

2. Corrêa RR, Murgel JMT, Piza JT, Ramos AS, Dias LCS, Morais LVC, Rosário FF. Dispersão de Biomphalaria straminea, hospedeira intermediária do Schistosoma mansoni, através da distribuição de peixes. Revista de Saúde Pública de São Paulo 4:117-127, 1970.

3. Croll NA. Human Behavior, Parasites, and Infectious Diseases. In: Croll NA, Cross JH (eds) Human Ecology and Infectious Diseases, Academic Press Inc., New York, p.1-20, 1983.

4. Guimarães $C T$, Souza $C P$, Soares $D M$, Araujo $N$, Schuster LMR. Occurrence of molluscs in aquaria of ornamental fishes in Belo Horizonte, Minas
Gerais, Brazil. Memórias do Instituto O swaldo Cruz 85:127-129, 1990.

5. Machado PA. The Brazilian Program for Schistosomiasis Control, 1975-1979. The American Journal of Tropical Medicine and Hygiene 31:76-86, 1982.

6. Paraense WL. Distribuição dos caramujos no Brasi.I In: Reis FA, Faria J, Katz N (eds) Modernos conhecimentos sobre a esquistossomose mansônica. In: Suplemento dos Anais de 1983/1984, Academia Mineira de Medicina, Belo Horizonte, p. 117-128, 1986.

7. Rey L. Parasitologia Médica. Guanabara Koogan, 2a ed, Rio de Janeiro, 1992.

8. Souza CP, Lima LC. Moluscos de interesse parasitológico do Brasil. Centro de Pesquisas René Rachou/FIOCRUZ, Belo Horizonte, 1990. 